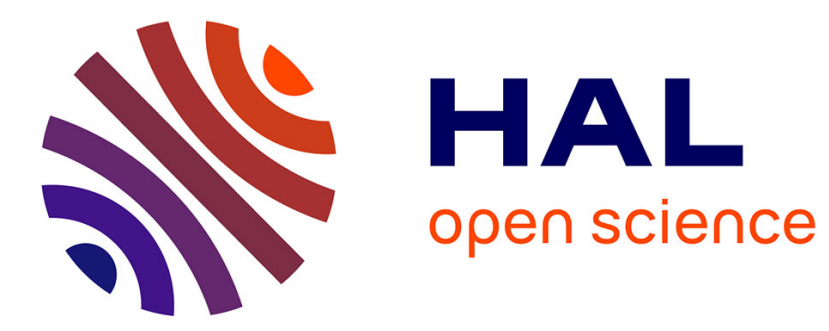

\title{
Designing Tactile Patterns using Programmable Friction
} Ludovic Potier, Thomas Pietrzak, Géry Casiez, Nicolas Roussel

\section{To cite this version:}

Ludovic Potier, Thomas Pietrzak, Géry Casiez, Nicolas Roussel. Designing Tactile Patterns using Programmable Friction. Proceedings of the AFIHM Conférence Francophone sur l'interaction HommeMachine (IHM 2016), Oct 2016, Fribourg, Switzerland. pp.1-7, 10.1145/3004107.3004110 . hal01383516

\section{HAL Id: hal-01383516 https://hal.science/hal-01383516}

Submitted on 18 Oct 2016

HAL is a multi-disciplinary open access archive for the deposit and dissemination of scientific research documents, whether they are published or not. The documents may come from teaching and research institutions in France or abroad, or from public or private research centers.
L'archive ouverte pluridisciplinaire HAL, est destinée au dépôt et à la diffusion de documents scientifiques de niveau recherche, publiés ou non, émanant des établissements d'enseignement et de recherche français ou étrangers, des laboratoires publics ou privés. 


\title{
Designing Tactile Patterns using Programmable Friction
}

\author{
Ludovic Potier ${ }^{1}$ \\ ${ }^{1}$ Aodyo \\ Thomas Pietrzak ${ }^{2}$ \\ Géry Casiez ${ }^{2}$ \\ Nicolas Roussel ${ }^{3}$ \\ ${ }^{2}$ Univ. Lille, France \\ ${ }^{3}$ Inria, France \\ potier.ludovic@gmail.com \{thomas.pietrzak, gery.casiez\}@univ-lille1.fr nicolas.roussel@inria.fr
}

\begin{abstract}
RÉSUMÉ
Les avancées récentes sur les technologies de frottement programmable permettent d'altérer la perception de friction d'une surface interactive, telle qu'un touchpad ou un écran tactile. Cependant, quelle que soit la technologie utilisée, ces effets ne permettent pas de reproduire les détails des surfaces physiques. De plus les effets sont appliqués à la surface entière, ce qui fait que tous les doigts touchant la surface reçoivent la même stimulation. Il y a actuellement peu d'études sur l'effet de ces limitations sur la perception de motifs représentés sur ces dispositifs. Nous présentons une étude qui compare la perception des textures tactiles avec un dispositif à frottement programmable (à effet squeeze film) et avec un support physique (cartes en papier imprimées). Nous montrons que malgré les limitations du frottement programmable, les participants interprètent les textures de manière similaire. Les différences apparaissent à la limite de la résolution d'entrée.
\end{abstract}

\begin{abstract}
Recent advances on programmable friction technologies make it possible to change the friction perception of an interactive surface such as a touchpad or a touchscreen However, regardless of the technology used, these effects cannot reproduce the fine grain sensation of physical surfaces. Moreover the effect is applied to the whole surface, so each finger exploring the surface feels the same sensation. Little is known about the impact of these limitations on the perception of patterns rendered on these devices. We present a study which compares the perception of tactile textures with a programmable friction device (squeeze film effect) and with a physical support (printed coated paper cards). We show that despite the limitations of programmable friction, participants interpret textures in a similar way. Differences occur at the limit of the input resolution.
\end{abstract}

\section{Author Keywords}

tactile; programmable friction; textures; patterns

\section{ACM Classification Keywords}

H.5.2 User Interfaces (e.g. HCI): Haptic I/O

\section{INTRODUCTION}

Programmable friction devices are getting a rising interest in both electronics and Human-Computer Interaction sciences, since they provide a new vocabulary for tactile elements, giving new opportunities for tactile interaction. They differ from other tactile interfaces, like vibrators or pin arrays, since they are passive interfaces, that is to say spatial exploration is required in order to feel the tactile signal. One advantage of programmable friction is that it is complementary to active interfaces [8]. Previous work on programmable friction focuses on enriching user experience when touching screens and objects [3], adding tactile feedback on GUIs [17], or enhance target acquisition in pointing tasks [7].

Research on tactile interfaces in general shows many examples of simulation of natural textures to increase immersion in virtual environments, mostly by reproducing vibration frequencies along with finger exploration on different materials $[20,14]$. Several studies focused on designing tactile icons, based on the parameters of the tactile signal, such as vibrations [6] forces [18] or pin arrays [24]. These icons convey information as abstract messages by mapping each parameter of the signal to a piece of information. There is currently no equivalent of tactile icons with programmable friction.

Implementation constraints make it difficult to reproduce the richness of sensations offered by physical objects. Their precision is limited by the input system accuracy, and the effect is applied on the whole interactive touch surface. Therefore, contrary to physical objects, programmable friction devices cannot provide different sensations to each finger. While this is certainly a strong limitation for simulations of natural textures, we wonder if it impacts the way people perceive programmable friction-based tactile icons.

To study this question we begin with a definition of tactile textures, before detailing a user study about the perception of tactile textures. In this study we compare the way participants interpret tactile textures, depending if they perceive it through a programmable friction device (STIMTAC [1]) or paper cards coated with sticky patterns.

\section{RELATED WORK}

The sense of touch makes it possible to feel various kinds of physical properties, such as weight, temperature, global or exact shape or texture [15]. Each property stimulates a particular kind of sensory receptor, which is better stimulated with particular movements and postures. Each kind of exploratory motion allows perceiving some of these properties. For example the weight of an object is better felt when holding it in the hand, temperature is easier felt through static contact. Textures are mostly felt with lateral
(C) ACM, 2016. This is the author's version of the work. It is posted here by permission of ACM for your personal use. Not for redistribution. The definitive version was published in Actes de la 28ème conférence francophone sur l'Interaction HommeMachine, 2016.

http://dx.doi.org/10.1145/3004107.3004110 
motion. While haptic exploration is a combination of many types of sensations, in the current study we will focus on friction.

There is currently no agreement on the definition of texture. Each field uses its own definition, that emphasizes the aspects they are interested in. The definition of a texture for paintings is different from its definition for material science or computer visualization. However they all have in common the multi-scale aspect, either for sound [9] or taste [32]. Studies also reveal this aspect for tactile textures [10].

In this paper, a tactile pattern refers to a spatial or temporal sequence of shapes distinguishable from a background, periodic or not (Figure 1). A texture combines several patterns on several dimensions or at different scales. Therefore textures have different levels of details.

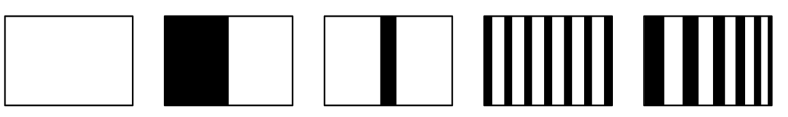

Figure 1: Example of patterns with increasing complexity, in one dimension: signal, step, shape, field, gradient.

\section{Texture perception}

The perception of tactile textures requires exploring the surface, mostly with a lateral motion [15]. It combines tactile perception and proprioception, through haptic or tactilekinesthetic perception [21]. The human haptic system is well adapted for texture perception [16]. Extensive research on tactile perceptual dimensions of textures focused on physical materials $[11,23]$. These studies revealed that granularity is an essential parameter for texture differentiation. This exhibits the multi-scale nature of textures. Most of the literature on texture perception focuses on material roughness [13], that is to say the micro-structure of the material. Studying the global perception of a texture implies considering both micro-structures and global variations in density or orientation of local elements. While the perception of touch involves both sensation of forces and tactile sensations, we focus on tactile sensations in this study.

The spatial combination of different patterns helps to distinguish parameters values. For instance it is possible to distinguish patterns that differ in orientation [12]. Density gradients consist in repeating the same pattern with a continuous progression of density. Studies show that density gradients of dots successfully represent positions and distances [30], and organizing gradients from low to high density increases pointing performance compared to high to low density ordering [26].

The temporal combination of tactile patterns has a great potential for conveying information. Although programmable friction devices allow displaying rhythmical patterns independent from exploration, we choose here not to focus on temporal parameters, but only on spatial ones. Related work on texture perception shows that important parameters for texture perception are thinness, orientation, friction variation and density variation of patterns [26]. Tactile shapes also need to be taken into consideration, considering the efficiency of Braille reading and tactile geometry for blind people.

\section{Encoding information with tactile cues}

Beyond the perception aspect, we are interested in interaction techniques that map information to tactile textures. Icons are common examples of representation of information with various modalities. Bernsen [4] describes the icon as a media with four properties: 1) static or dynamic; 2) linguistic or not, divided in lexical, syntactic and semantic aspects; 3) analogous or not, corresponding to the likeness between representation and represented ; 4) arbitrary or not, that is to say based on an preexisting semantic system.

The first focus when designing icons is to identify the lexical and syntactic aspects, since they describe the vocabulary of stimulations, and the way they are combined. This work requires knowledge about distinction and identification thresholds [18]. Then the focus is to design a systematic mapping between these tactile cues and information $[25,24]$. This methodology enabled the creation of auditory icons [5], vibratory icons [28, 6] or pin-array icons $[25,24]$. There is no such tactile icons system for programmable friction in the literature. In order to achieve this goal, we need better knowledge about the parameters of tactile patterns. This is the focus on our user study.

\section{Programmable friction technology}

Two technologies are known to vary friction on a surface: electro-vibration [31,2] and squeeze film effect [1, 17]. Even if their operation mode is quite different, the resulting effect is similar. It consists in varying friction on a surface, modifying fingers sliding conditions. Roughness consists in a material property, relative to the surface conditions. It influences friction, which is a physical interaction between two surfaces in contact, opposed to their relative motion [29]. Programmable friction devices allow to modulate friction on a surface. The range of frictions with both technologies is limited, but the frontier between zones with different friction appears to be easy to perceive, provided the difference is sufficient [27].

The Squeeze film effect consists in creating a thin air cushion between the finger and the surface, which reduces friction. In the case of STIMTAC [1] and LatPad [17], this squeeze film effect is produced by the controlled vibration of a surface at a very high frequency with piezoelectric ceramics. These frequencies are far beyond the sensible frequencies of the skin's mechanoreceptors. Users do not feel the vibration, but its effect on the tribology. As a limitation, these devices can produce a disturbing buzz if the frequency is within the auditory range (up to $20 \mathrm{kHz}$ ). The technology works with different materials such as glass or metals. However the surface has to be rigid to transmit vibrations correctly.

\section{EXPERIMENT}

Using programmable friction both aims at reproducing friction properties of objects, or encode information with an abstract mapping of friction parameters. The stimulation created with programmable friction devices have subtle differences compared to tangible surfaces. For example, when touching a rough surface with a finger, we can feel several small bumps under the fingertip at the same time. 


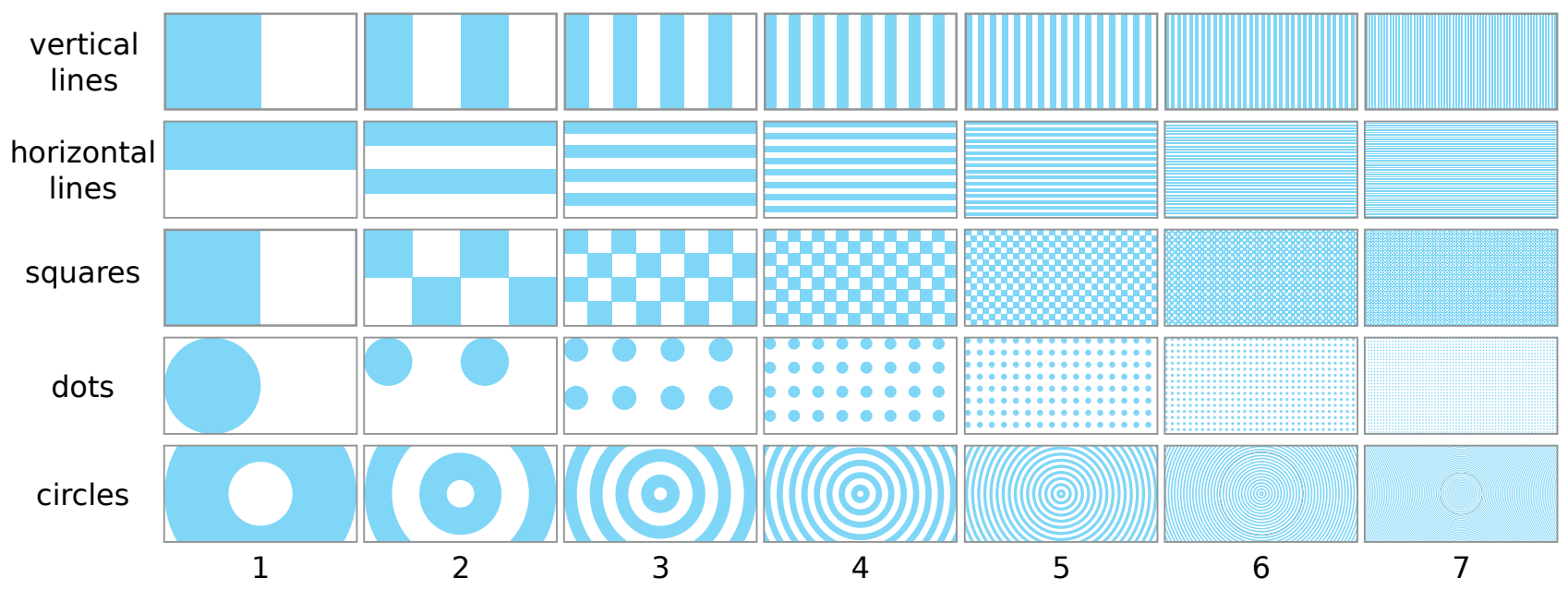

Figure 2: All shapes: vertical lines, horizontal lines, squares, dots and circles; for all densities: 1 to 7 . Vertical lines 1 and squares 1 is the same pattern.

Existing programmable devices produce a single stimulation at a time. Therefore the sensation described before is simulated when the finger is sliding on the surface. We would like to know if it influences the interpretation of tactile patterns. In this experiment we compare the perception of tactile patterns with a programmable friction device and with a physical object. It will help to draw design guidelines for researchers who would like to improve the technology, as well as researchers who would like to understand what people can perceive with such devices.

\section{Methodology}

In this experiment we use a STIMTAC programmable friction device, and $250 \mathrm{~g}$ dull coated paper cards for the tangible surface. The stimulation on the paper is created with a transparent ink, which feels stickier than the paper. The stickiness depends on the number of printed layers, printed with a HP Indigo Digital Press ${ }^{\circledR}$ printer. We performed a pilot study with 3 users to define the number of layers required to match the stimulation with the STIMTAC. We opted for 30 layers, which makes a $0.05 \mathrm{~mm}$ thickness. Both STIMTAC and cards have the same size: $8 \mathrm{~cm}$ wide and $4 \mathrm{~cm}$ high.

We focused on two parameters of patterns, namely the SHAPE (5 values, Figure 2, rows) and DENSITY (7 values, Figure 2, columns). The combination of these two parameters makes 34 samples (the low density square is the same as the low density vertical line). The rationale for the shape selection was to explore patterns which feel different depending on the direction of the exploratory movement (vertical and horizontal lines) or shapes which feel the same on different orientations (squares and dots) or which should feel the same regardless of the orientation (circles). Regarding density, we started with the lowest density for which there is only one shape. Then each new density value doubles the pattern.

The experiment consisted in a cluster-sorting task [22]. The users were presented the 34 samples, either with 34 paper cards (Figure 3 top) or with a user interface (Figure 3 bottom). Users were allowed to explore each sample

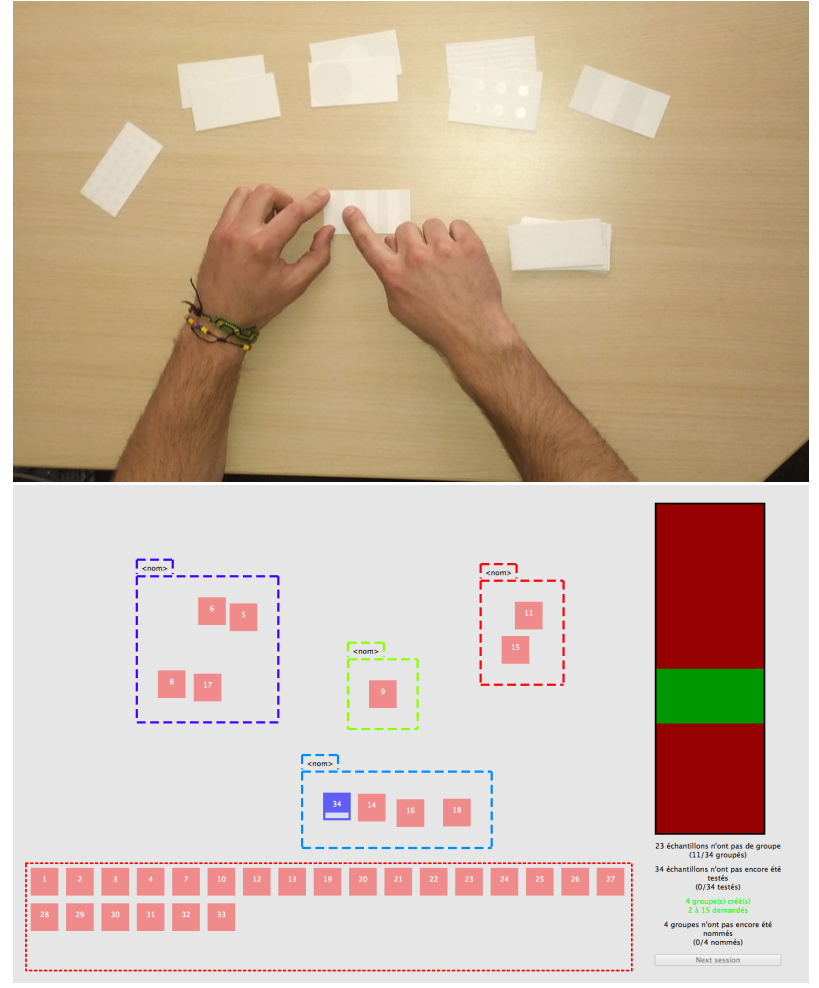

Figure 3: Cluster-sorting task with paper cards (top) or with the stimtac (bottom)

as much as they wanted, in multiple directions with the index finger of their dominant hand. In the paper condition, they wore translucent glasses, which let the participants see the location of paper cards and their hand but not the pattern printed on the cards (the ink is transparent but slightly shiny). This allowed participants to manipulate cards and make groups with spatial memory without having hints from visual cues. In both tasks they wore a noise-cancellation headset to avoid audio clues influence on their answers. 


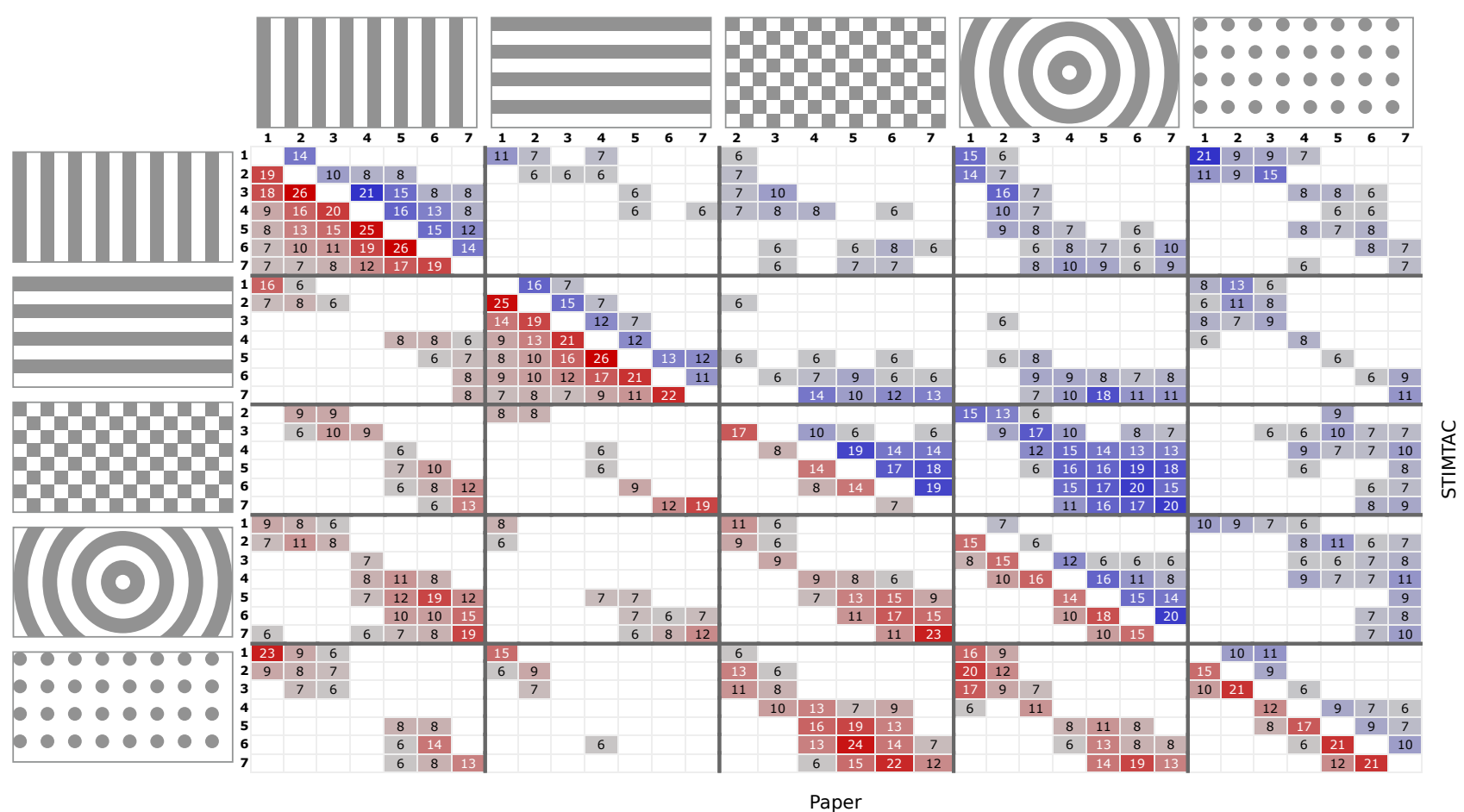

Figure 4: Comparison of grouping occurrences for every pair of pattern, between paper (red) and STIMTAC (blue). The numbers indicate how many times each pair was in the same group.

The experiment followed a between subject design to prevent influences of grouping strategies from one condition to the other. We recruited 12 participants ( 9 males) through mailing lists, between 24 and 54 years old for the paper condition, and 12 participants ( 9 males) between 19 and 42 years old for the STIMTAC condition. We followed a standard protocol [19]. They were instructed to group the samples, the number of groups varying in each of the three phases of the experiment. In the first phase the participants were free to choose a number of groups between 2 and 15 In the two other phases they were instructed to make 5 , 10 or 15 groups in a random order, with exception to the closest number to the number of groups they made in the first phase. For example if a participant made 7 groups in the first phase, the second and third phases were with 10 and 15,5 being closer to 7 than 10 and 15 . We also asked participants to name the groups they made in order to get insights on their grouping strategies.

\section{Results and discussion}

We report in Figure 4 the number of times each pair of pattern was grouped together. We observe that vertical and horizontal lines are often grouped per shape, whether with paper or the STIMTAC. Our explanation is that these patterns are easy to perceive and distinguish from others. The fact that they feel different whether we explore them horizontally or vertically is an essential cue for distinction. Dots have a similar strategy for both STIMTAC and paper. They are often grouped with vertical lines and circles at low densities, with squares for high densities and with other dots of similar densities. These patterns are very similar for the density ranges mentioned. This does not necessarily mean users cannot distinguish them, but they feel a similar sensation, which motivates them to group them together. Interestingly, circles are grouped differently for paper and STIMTAC. Circles of high densities are grouped with vertical lines when explored on the paper, and with squares when explored on the STIMTAC. This difference is probably due to a difference of perception. On the left and right sides of the pattern, circles are similar to vertical lines, and at the middle there is a small portion that feels like horizontal line. The fine details are harder to perceive with the STIMTAC than with the paper. The fact that participants felt high densities circles as squares means that they felt a combination of vertical and horizontal patterns across the surface, rather than at specific locations on the pattern.

\section{MDS analysis.}

Initially we performed a Multidimensional Scaling (MDS) analysis. We hypothesized that participants will either group patterns per shape or per density. For a shape strategy we expected to see five clusters, each one for one shape, and grouping all densities together, or the inverse. We were also wondering if the grouping strategy would be similar with the paper or with STIMTAC. The distance between each sample was calculated as follows. For each phase of every participant, the distance between two sample is 0 if the samples were in the same group, 1 otherwise. The overall distance is the sum of all distances in every phase of every participant.

We used the cmdscale function of the R software, which uses a principal coordinates analysis. The goodness of fit we obtain with a 2-dimensions mapping is low $(\mathrm{GOF}=0.40,0.43$ for paper, $\mathrm{GOF}=0.28,0.28$ for STIMTAC). An MDS analysis would require 6 dimensions to have a fair goodness of fit with paper $(\mathrm{GOF}=0.76,0.81)$ and 12 


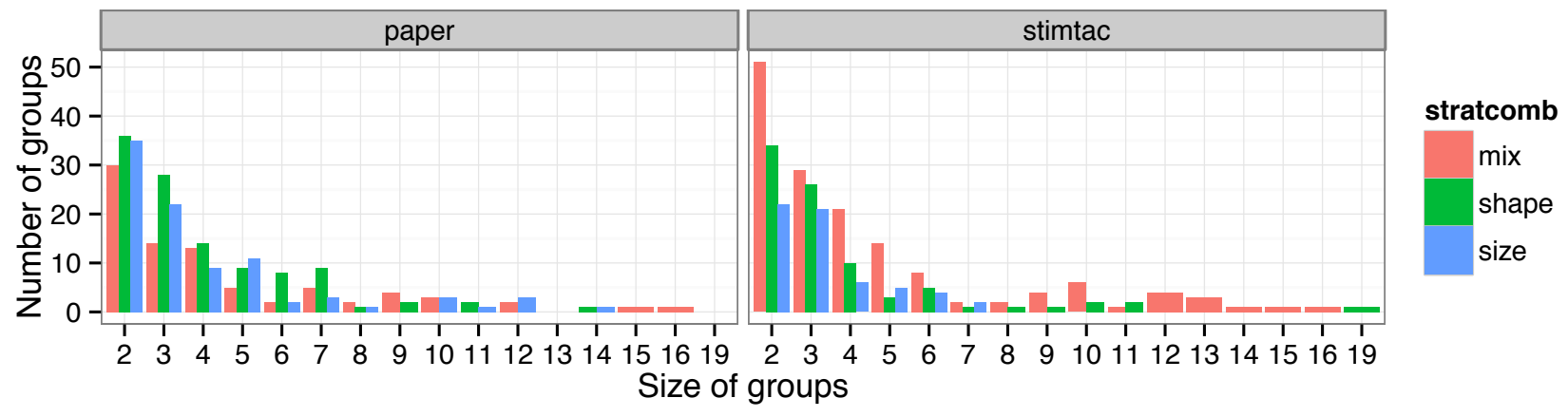

Figure 5: Grouping strategies per group size on paper (left) and STIMTAC (right)

for STIMTAC $(\mathrm{GOF}=0.74,0.75)$. This means that contrary to our hypothesis, there is probably no dominant grouping strategy among users and conditions. We use another approach to investigate further the results.

\section{Grouping strategy analysis.}

For each group participants made, we would like to know if the strategy was to group patterns of the same SHAPE, patterns of the same DENSITY, or a MIX. Therefore for each group, we computed two metrics: 1) the maximum occurrence of a SHAPE and DENSITY within the group, 2) the number of different SHAPES and DENSITIES within the group. We normalize measures since there are 5 SHAPES and 7 DENSITIES. We consider the group was made with a SHAPE strategy if the maximum occurrence of SHAPE is greater than the maximum occurrence of DENSITY, and the number of different SHAPES is lower than the number of different DENSITIES. If one of the metrics is equal for both parameters, or if the two criteria give a different strategy we consider the strategy as MIX. Figure 5 shows the strategies occurrences for each group size for both conditions. We did not plot groups containing only one pattern (17.7\% of groups).

First of all $92 \%$ of groups have at most 7 items. This is certainly related to the fact that the two parameters have 5 and 7 levels. It suggests that participants tried to use either a SHAPE or DENSITY strategy. We can observe on the paper condition that groups of 6 and 7 items are mostly made with a SHAPE strategy, which means users made groups of the same SHAPE, with up to 7 different DENSITIES. We do not observe this phenomenon in the STIMTAC condition, which means that participants have more difficulties to distinguish the 7 levels.

The results also exhibit a difference in strategies between paper and STIMTAC. While the strategies for groups of 2 to 5 items are rather equal with paper, participants use more often a MIX strategy. Since participants of the paper condition do not favour the MIX strategy, there is little chance participants of the STIMTAC condition deliberately use a MIX strategy. Therefore this is most likely due to the difficulty to distinguish these patterns.

\section{Discussion.}

Overall, participants were able to identify shapes and densities, both with the paper and the programmable friction device. They mostly interpret patterns with both methods in a same way. They used different strategies only when patterns had fine details, which suggests that differences occur at the limit of the input and output resolution of programmable friction devices. The whole device produces the same sensation across the device regardless the finger location. This means that the output refresh rate, input rate and input resolution contribute to the signal actually produced. Our results suggest that these limits have an impact on the interpretation of the patterns represented.

On a methodological point of view we see that except at the limits of the device capabilities, the interpretation of simple patterns with a programmable friction device or with a physical surface is similar. This means for example that paper cards can be used for prototyping such interactions for a best case scenario.

On a perception point of view, we remind that this result stands with a one finger exploration. This means we do not exploit the richness of large surfaces and the ability to feel different sensations at the same time on different fingers. We are not aware of any technology able to produce such effects. Many studies, especially with visually impaired users take advantage of this capability, with embossed paper for example. We also remind that programmable friction devices like the STIMTAC we used cannot produce edge sensations, because it requires to feel two different sensations under the finger. This limitation did not have a particular effect on our results. It could be an issue for a realistic simulation of physical textures. In our case we do not require a realistic sensation.

\section{CONCLUSIONS}

We proposed a definition for tactile textures, and initiated a series of studies towards a classification of tactile parameters for variable friction. We compared the perception of tactile textures on a tangible object (printed paper card) and with a programmable friction device (STIMTAC). Our results show that users essentially perceive textures in a similar way. Differences occur at the limits of the technology, such as when representing particular shapes with fine details (high density circles). Interestingly, the approach we proposed which consists in using printed paper cards to experiment the properties of tactile friction is valid. It allows the exploration of the concept independently of the current limitations of the technology. We recommend to use this approach for futures studies on the topic. Such results can guide the design of future programmable friction devices. 


\section{ACKNOWLEDGEMENTS}

This work took place as part of the Touchit project with financial support from Oséo, the Nord - Pas de Calais Region and the European regional development fund (ERDF).

\section{BIBLIOGRAPHIE}

1. Michel Amberg, Frédéric Giraud, Betty

Lemaire-Semail, Paolo Olivo, Géry Casiez, and Nicolas Roussel. 2011. STIMTAC, a tactile input device with programmable friction. In Proc. of UIST 11. ACM, 7-8.

http://dx. doi .org/10.1145/2046396.2046401

2. Olivier Bau, Ivan Poupyrev, Ali Israr, and Chris Harrison. 2010. TeslaTouch: electrovibration for touch surfaces. In Proc. of UIST '10. ACM, 283-292. http://dx.doi .org/10.1145/1866029.1866074

3. Olivier Bau, Ivan Poupyrev, Mathieu Le Goc, Laureline Galliot, and Matthew Glisson. 2012. REVEL: tactile feedback technology for augmented reality. In Adjunct proc. of SIGGRAPH '12. ACM, $17: 1-17: 1$.

http://doi.acm.org/10.1145/2343456.2343473

4. N. O. Bernsen. 1993. Modality Theory In Support Of Multimodal Interface Design. In ERCIM Workshop on Multimodal HMI. 37-44. http://www.nislab.dk/ Publications/MOD-THEORY-21.1.94-F.pdf

5. Stephen A. Brewster, Peter C. Wright, and Alistair D. N. Edwards. 1993. An evaluation of earcons for use in auditory human-computer interfaces. In Proc. of INTERCHI'93. ACM, 222-227.

http://dx.doi .org/10.1145/169059.169179

6. Lorna M Brown, Stephen A Brewster, and Helen C Purchase. 2006. Multidimensional tactons for non-visual information presentation in mobile devices. In Proc. of MobileHCI '06'. 231-238. http: //dx. doi . org/10.1145/1152215.1152265

7. Géry Casiez, Nicolas Roussel, Romuald Vanbelleghem, and Frédéric Giraud. 2011. Surfpad: Riding Towards Targets on a Squeeze Film Effect. In Proc. of CHI'11. ACM, 2491-2500. http: //doi . acm. org/10.1145/1978942.1979307

8. Xiaowei Dai, Jiawei Gu, Xiang Cao, J. Edward Colgate, and Hong Tan. 2012. SlickFeel: sliding and clicking haptic feedback on a touchscreen. In Adjunct proc. of UIST'12. 21-22.

http://doi.acm.org/10.1145/2380296.2380308

9. Shlomo Dubnov, Ziv Bar-Joseph, Ran El-Yaniv, Dani Lischinski, and Michael Werman. 2002. Synthesizing Sound Textures through Wavelet Tree Learning. Computer Graphics and Applications 22, 4 (2002), 38-48. http: //dx.doi.org/10.1109/MCG.2002.1016697

10. Mark Hollins, Slimane J. Bensmaïa, Kristie Karlof, and F. Young. 2000. Individual differences in perceptual space for tactile textures: evidence from multidimensional scaling. Perception and Psychophysics 62, 8 (2000), 1534-1544. http://www.ncbi.nlm.nih.gov/pubmed/11140177
11. Mark Hollins, Richard Faldowski, Suman Rao, and Forrest Young. 1993. Perceptual dimensions of tactile surface texture: A multidimensional scaling analysis. Attention, Perception, \& Psychophysics 54, 6 (1993), 697-705. http://dx. doi . org/10. 3758/BF03211795

12. Barry Hughes. 2006. Haptic exploration and the perception of texture orientations. Haptics-e 4 (2006). http://www . haptics-e.org/Vol_04/he-v4n2 .pdf

13. Barry Hughes, Jin Wang, Daryan Rosic, and Katie Palmer. 2007. Texture Gradients and Perceptual Constancy under Haptic Exploration. In Proc. of WorldHaptics '07. IEEE, 66-71. http://dx.doi.org/10.1109/WHC. 2007.109

14. Masashi Konyo, Satoshi Tadokoro, Akinori Yoshida, and Naoki Saiwaki. 2005. A tactile synthesis method using multiple frequency vibrations for representing virtual touch.. In Proc. of IROS 05. IEEE, 3965-3971. http://dx.doi . org/10.1109/IROS. 2005. 1545130

15. S. J. Lederman and R. L. Klatzky. 1987. Hand movements: A window into haptic object recognition. Cognitive Psychology 19 (1987), 342-368. http: //dx. doi . org/10 . 1016/0010-0285(87)90008-9

16. S. J. Lederman and R. L. Klatzky. 2009. Haptic perception: a tutorial. Attention, Perception and Psychophysics 71, 7 (2009), 1439-1459. http://dx.doi.org/10.3758/APP.71.7.1439

17. V. Levesque, L. Oram, K. MacLean, A. Cockburn, N. D. Marchuk, D. Johnson, J. E. Colgate, and M. A. Peshkin. 2011. Enhancing physicality in touch interaction with programmable friction. In Proc. of CHI'11. 2481-2490.

http: //dx. doi . org/10.1145/1978942 . 1979306

18. K. MacLean. 2008. Foundations of Transparency in Tactile Information Design. IEEE Trans. on Haptics 1, 2 (2008), 84-95

http://dx. doi . org/10.1109/TOH. 2008.20

19. K. Maclean and M. Enriquez. 2003. Perceptual design of haptic icons. In Proc. of Eurohaptics '03. 351-363. http:

//www . eurohaptics.vision. ee. ethz.ch/2003/27.pdf

20. Allison M. Okamura, Jack T. Dennerlein, and Robert D. Howe. 1998. Vibration Feedback Models for Virtual Environments. In Proc. of ICRA 98. 674-679.

http://dx.doi . org/10.1109/ROBOT. 1998.677050

21. K.E. Overvliet, K.M. Mayer, J.B.J. Smeets, and E. Brenner. 2008. Haptic search is more efficient when the stimulus can be interpreted as consisting of fewer items. Acta Psychologica 127, 1 (2008), 51--56. http://www. sciencedirect.com/science/journal/ $00016918 / 127 / 1$

22. J. Pasquero, J. Luk, S. Little, and K. Maclean. 2006. Perceptual analysis of haptic icons: an investigation into the validity of cluster sorted mds. In Proc. of Haptics '06. IEEE, 437-444. http://dx . doi . org/10.1109/HAPTIC. 2006. 1627122 
23. Delphine Picard, Catherine Dacremont, Dominique Valentin, and Agnes Giboreau. 2003. Perceptual dimensions of tactile textures. Acta psychologica 114, 2 (2003), 165-184.

http: //dx . doi . org/10.1016/j . actpsy . 2003.08.001

24. Thomas Pietrzak, Andrew Crossan, Stephen A. Brewster, Benoit Martin, and Isabelle Pecci. 2009. Creating Usable Pin Array Tactons for Non-Visual Information. IEEE Trans. on Haptics 2, 2 (2009), 61-72. http://dx. doi .org/10.1109/TOH. 2009.6

25. Thomas Pietrzak, Isabelle Pecci, and Benoit Martin. 2006. Static and dynamic tactile directional cues experiments with VTPlayer mouse. In Proc. of Eurohaptics '06. 63-68. http://hal.inria.fr/hal-00671517

26. L. Potier, O. Gapenne, X. Liu, and D. Aubert. 2011. The effect of the direction of a gradient on haptic pointing in a 2D virtual environment. In Proc. of IADIS Interfaces and HCI '11. 438-441. http: //www.gbv.de/dms/tib-ub-hannover/666354472 .pdf

27. L. Potier, T. Pietrzak, G. Casiez, and N. Roussel. 2012. Méthodologie de conception de textures pour les interfaces tactiles à frottement programmable. In
Ergo'IHM 2012. ACM, 132-139.

http://doi . acm.org/10.1145/2652574.2653420

28. A.F. Rovers and H.A. van Essen. 2004. HIM: a framework for haptic instant messaging. In Proc. of CHI '04. 1313-1316.

http://dx. doi . org/10.1145/985921.986052

29. M. Sahin, C. S. Çetinarslan, and H. Erol Akata. 2005. Effect of surface roughness on friction coefficients during upsetting processes for different materials. Materials and Design 28 (2005), 633-640. Issue 2. http://dx. doi . org/10.1016/j . matdes . 2005.07.019

30. R. Schellingerhout, A. W. Smitsman, and G. P. Van Galen. 1998. Texture information in tactual space perception. Acta Psychologica 99 (1998), 93-114. http: //dx. doi .org/10.1016/S0001-6918(98)00004-3

31. R. M. Strong and D. E. Troxel. 1970. An electrotactile display. In Trans. on Man-Machine Systems (IEEE). 72-79. http://dx. doi . org/10. 1109/TMMS . 1970. 299965

32. Alina Surmacka Szczesniak. 2002. Texture is a sensory property. Food Quality and Preference 13, 4 (2002), 215-225.

http: //dx . doi . org/10 . 1016/S0950-3293(01)00039-8 